issn: $1808-799 X$

ano 6 - número 7 - 2008

\title{
A PRIMEIRA REPÚBLICA EM PORTUGAL (1910 - 1933) E OS DIREITOS DOS TRABALHADORES ${ }^{1}$
}

\section{Cristina Rodrigues - cristina.rodrigues@iefp.pt}

A República em Portugal foi implantada pelo golpe militar de 5 de Outubro de 1910, que destituiu o Rei D. Manuel II e com ele um regime monárquico em grandes dificuldades. De 1910 a 1933 o país viveu um dos períodos mais conturbados da sua história, sucedendo-se governos uns após os outros, numa enorme instabilidade política. A participação na 1를 Grande Guerra mundial agravou a difícil situação económica do país, cuja população vivia maioritariamente em péssimas condições sociais. A transição entre o período republicano e o Estado Novo de Oliveira Salazar, consolidado em 1933, com a nova Constituição política, fazse através de uma ditadura militar, também ela mesma instável.

O período a estudar, 1910 a 1933, é, pois, do ponto de vista político-social particularmente difícil. Apesar desta característica, foi um momento da história de Portugal em que houve um progresso evidente quanto aos direitos dos trabalhadores consagrados pela lei.

Recorde-se que um dos temas mais recorrentes à época, suscitando vivos debates e grande agitação social, era a questão das condições de vida dos trabalhadores. Não se trata, certamente, de uma especificidade nacional. Este era também o quadro geral na Europa, que correspondia a uma crescente preocupação com as questões sociais, podendo apontar-se vários momentos marcantes como a publicação da Encíclica Rerum Novarum do Papa Leão XIII (1891), a criação da Associação Internacional para a Protecção Legal dos Trabalhadores (1901) ou ainda a fundação da Organização Internacional do Trabalho (1919).

Para além do interesse histórico no estudo das condições de trabalho em Portugal no período da I República e ditadura militar, moveu-me, na investigação que levei a cabo, a intenção de conhecer melhor o passado, esperando que a história nos interpele, nos ajude a compreender o presente e a antecipar caminhos para o futuro.

\footnotetext{
${ }^{1}$ Este artigo foi elaborado com base na dissertação de Mestrado em Sociologia do Trabalho das Organizações e do Emprego, Trabalhar em Portugal (1910-1933) - análise da legislação sobre direitos dos trabalhadores que defendi no ISCTE em Abril de 2007.
} 
issn: $1808-799 X$

ano 6 - número 7 - 2008

Baseei-me como tema orientador na análise da legislação sobre os direitos dos trabalhadores em Portugal, no período entre 1910 e 1933. O olhar incide sobre a evolução desta legislação, que identifiquei e analisei na sua especificidade própria, como a consagração de um discurso histórica e juridicamente possível. Não pretendo apresentar as reais conquistas dos trabalhadores portugueses neste período - a lei e a realidade que pretende regular não se podem confundir. Assim, apresentarei um balanço dos direitos legalmente consagrados no período republicano, divididos por três grandes áreas temáticas - Higiene, saúde e segurança no trabalho, Trabalho das mulheres e dos menores, Horário de trabalho.

Para não ficar confinada a uma visão estritamente legal, acompanho este balanço da evolução do quadro normativo de uma síntese dos ecos suscitados na sociedade, designadamente nos congressos operários interprofissionais e na imprensa generalista, particularizando-se, no caso desta, um normativo representativo de cada uma das grandes áreas temáticas. Seguem-se algumas considerações genéricas e de conjunto sobre os resultados apresentados.

Finalmente, apresento algumas notas para uma leitura contemporânea, ensaiando um paralelismo com os dias de hoje.

\section{1 - 0 quadro normativo}

Higiene, saúde e segurança no trabalho.

Sobre esta temática, podemos falar de um grande avanço legislativo. Na verdade, quanto aos normativos respeitantes a condições de salubridade e manipulação de matérias perigosas, tínhamos em vigor, a 5 de Outubro de 1910, para além de alguns decretos relativos a actividades concretas de especial perigosidade, um diploma genérico, do ano de 1863, já na altura desactualizado, um decreto de 1891 e um regulamento de 1893, ambos referentes ao trabalho das mulheres e dos menores na indústria, que continham algumas normas referentes a esta matéria. Excluindo três decretos de alcance limitado entretanto publicados, é apenas em 1918 que temos um diploma de carácter genérico, visando regular toda a actividade industrial em matéria de condições de salubridade dos lugares de trabalho, higiene e segurança dos operários e higiene, salubridade e segurança pública. $\mathrm{O}$ âmbito de abrangência deste decreto viria a ser amplificado por um regulamento publicado em 1922, que determina a sua aplicação não só às indústrias, como aos estabelecimentos comerciais e "em geral a todos os locais onde se exerce um trabalho profissional".

Os acidentes de trabalho, em 1910, não estavam regulados no ordenamento jurídico português, a não ser no Código Civil. Apesar da obrigatoriedade de comunicação dos acidentes ocorridos, na verdade apenas existia responsabilidade por parte da entidade patronal 
issn: $1808-799 \mathrm{X}$

ano 6 - número 7 - 2008

face ao operário acidentado caso se viesse a provar a culpa ou negligência daquele, o que tornava, na generalidade dos casos, a indemnização um acto voluntário e dependente da consciência social do patrão. Como se dizia no preâmbulo do decreto ํㅜㄴ 5637, de 7 de Maio de 1919: "a indemnização pelo desastre de trabalho, em Portugal era apenas uma platónica disposição do Código Civil". No caso das doenças profissionais nada era previsto na lei.

Quanto a esta temática o grande marco foi a publicação da lei oㅡ 83, de Julho de 1913, que teve grande impacto ao prever o direito a assistência clínica, medicamentos e indemnizações às vítimas dos acidentes de trabalho. Era baseada na teoria do risco profissional, tal como a generalidade das legislações congéneres. Constituiu no dizer do legislador de 1919: "uma das melhores iniciativas da República até agora decretadas como medida de protecção às classes trabalhadoras". Este regime seria alargado pela legislação de Maio de 1919, ao estabelecer a protecção não só nos desastres de trabalho, como também na doença. $\mathrm{O}$ alcance e a cobertura de todas as actividades, quer na doença ("é obrigatório o seguro social obrigatório na doença para os indivíduos de ambos os sexos, que exerçam qualquer profissão nos domínios da actividade humana, reconhecida como digna e honesta pelos usos e costumes e sancionada pelas leis vigentes" - ver decreto ํㅜ 5636 , de 7 de Maio de 1919), quer nos acidentes ("tornando extensivas a todas as profissões as responsabilidades em todo o risco" - ver decreto ํㅡ 5637, de 7 de Maio de 1919), fazem deste conjunto de legislação um marco na história da proteç̧ão dos trabalhadores, como aliás o próprio preâmbulo deste decreto refere: "fica sendo agora, também, um dos sólidos fundamentos em que tem de assentar o novo estado social criado pela República, para tornar menos tormentosa a vida dos que só no trabalho intelectual ou no seu braço encontram a única garantia da manutenção da existência".

Nesta matéria Portugal viria a ratificar, em Março de 1929, as convenções da OIT sobre reparações de desastres de trabalho e doenças profissionais. No entanto, à data da instauração do Estado Novo, o quadro normativo era basicamente o definido pela legislação de 1919.

De que modo eram reflectidas as preocupações com a higiene e segurança nos congressos operários interprofissionais? Verificamos que estão implícitas em todos os discursos sindicais; com excepção, porém, do congresso de 1925, em que se constitui como objecto de uma tese, não temos senão referências mediatas ao tema, não existindo memória escrita de repercussões da produção legislativa sobre este tema.

O normativo legal escolhido para ilustrar os ecos desta temática na imprensa generalista foi a lei ํo 83, de Julho de 1913. Os dois jornais de Lisboa, o Diário de Notícias e O Século noticiam, no dia, a publicação da lei. Dias mais tarde $O$ Século publica uma detalhada 
issn: $1808-799 \mathrm{X}$

ano 6 - número 7 - 2008

entrevista com o autor da lei, cujo discurso remete para a eterna comparação com a Europa. A promessa desta lei vinha de 1908, ano em que o seu autor fora eleito pelos setubalenses para o parlamento e constituía, portanto, nas suas palavras, uma "sagrada promessa e uma grande obra da humanidade". Voz dissonante chega-nos de O Comércio do Porto, que não noticia a publicação da lei, mas duas semanas depois, em editorial, apresenta uma longa reflexão sobre o incumprimento das leis, apontando para o provável incumprimento futuro da lei $n^{\circ}=83$ e apresentando as críticas ao diploma feitas pela Associação Industrial Portuense e pela Associação Industrial Portuguesa.

\section{Trabalho das mulheres e dos menores.}

Em Outubro de 1910 o quadro legal era muito limitado quanto a esta matéria e datava de 1891. A transposição da convenção internacional para a proibição do trabalho nocturno das mulheres empregadas na indústria ocorre em Junho de 1911. Apesar de o seu âmbito de abrangência se limitar às actividades industriais, e dentro destas às unidades com mais de 10 trabalhadores, constituiu um marco e uma referência para a legislação subsequente. A lei oㅜ 297, de Janeiro de 1915, vem introduzir alterações no quadro legal de 1891, que se manteve, todavia, em vigor. Com vista a uma maior protecção dos menores introduz-se maior rigor, pelo menos na letra da lei, a nível de cumprimento de horário de trabalho, higiene e segurança e controlo administrativo da respectiva prestação de trabalho. No entanto, continua a ser perfeitamente legal trabalhar aos 10 anos completos, desde que se tenha o exame do $1^{\circ} \mathrm{grau}$, compleição física robusta e se ocupe de serviços leves; é legal trabalhar, mesmo sem reunir estas condições, aos 12 anos, desde que não se excedam as 10 horas por dia e as 60 por semana. Quanto à protecção da maternidade tudo se mantém igual, ou seja, a proibição de trabalhar nas 4 semanas a seguir ao parto, sem remuneração, e a possibilidade de, voltando ao serviço, em determinadas condições, poder amamentar o filho, ausentando-se para o efeito.

Este regime só viria a ser alterado em 1927. O preâmbulo do decreto o 14498 é sintomático de uma forma diferente de pensar a protecção das mulheres e dos menores e, para além de considerações várias, remete para o Acordo de Washington, de 29 de Outubro de 1919, de cuja transposição para o espaço nacional se ocupa, "não esquecendo as condições especiais do nosso meio, a fim de produzir obra útil e que se possa realizar". De reter a proibição legal de trabalhar antes dos 12 anos e a inclusão de uma cláusula geral de protecção, que abrange menores, mulheres, grávidas e mães que amamentam, que estipula que só devem empregar-se em "trabalhos exigindo um esforço moderado na forma e na duração, e que não comprometam o seu desenvolvimento físico e intelectual, nem a sua moralidade". Os trabalhos subterrâneos são liminarmente proibidos e os trabalhos nocturnos 
issn: $1808-799 X$

\section{ano 6 - número 7 - 2008}

também, salvo, neste caso, excepções previstas por lei. O período de pós-parto mantém-se em 4 semanas, não podendo contudo haver redução ou suspensão de salário, o que constitui uma grande melhoria. Em traços gerais era este o quadro normativo existente no que se refere ao trabalho de mulheres e menores aquando da instauração do Estado Novo.

Nos congressos operários são algumas as referências ao trabalho das mulheres e dos menores. Contudo, apenas em 1909, antes portanto da implantação da República, e em 1925, este tema se constitui como objecto autónomo de teses apresentadas. De resto são referências implícitas, semeadas em discursos que versam sobre muitos outros temas, designadamente sobre a organização sindical e operária.

No que respeita à imprensa generalista foi escolhida a lei nํㅡㄹ, de Janeiro de 1915. Curiosamente nem uma só referência encontrámos a esta lei, o que se poderá dever ao facto de não se tratar de uma lei nova, mas um conjunto de alterações ao quadro normativo de 1891. Contudo, é de assinalar que, as outras duas leis publicadas no mesmo dia, sobre o horário de trabalho, mereceram honras de imprensa, o que leva a suspeitar da pouca importância atribuída ao tema pelos periódicos.

Quanto à matéria do trabalho das mulheres e dos menores, afigura-se pertinente assinalar uma questão que transcende a consagração legal dos direitos destes grupos de trabalhadores. Trata-se da controvérsia profunda na sociedade portuguesa sobre a legitimidade do acesso das mulheres e dos menores ao mercado de trabalho, vistos como "concorrentes", mais baratos, à mão-de-obra masculina, numa época de frequentes e graves crises de trabalho.

$\mathrm{Na}$ verdade, a par da visão igualitária sobre o papel de mulheres e homens que está presente na ideologia libertária e sindical, o humanismo igualitarista de que nos fala João Freire (1992, p. 364), surge uma corrente que condena a participação das mulheres no mercado de trabalho, seja por razões alegadamente altruístas de protecção de género, seja por razões de protecção do próprio mercado, já que as mulheres eram vistas como uma ameaça aos postos de trabalho e ao nível salarial dos homens.

Evidências desta tensão social são frequentes nos documentos que consultámos, seja na imprensa operária, seja na generalista. Apenas como apontamento citaremos um artigo sobre a crise de trabalho na indústria corticeira, publicado em $O$ Corticeiro a 3 de Outubro de 1929:

"Duas iniciais de duas palavras que mais directamente contribuem para a crise de trabalho que a classe corticeira vem atravessando, $\mathrm{M}$ e $\mathrm{M}$ quer dizer máquinas e mulheres. [...]

Muito embora o rendimento de trabalho da mulher na fábrica seja muito inferior ao do homem, e muito menos consciencioso, vêem os senhores 
issn: $1808-799 \mathrm{X}$

ano 6 - número 7 - 2008

Industriais, nas mulheres, a forma de poderem conseguir mais lucros pelo barateamento da mão-de-obra, e que acontece? Acontece que o trabalho escasseia para os homens, e a crise faz-se sentir com intensidade, levando a alguns lares a privação e a fome.

Que devemos então fazer? Evitar a entrada das mulheres nas fábricas. [...]

Acabemos, pois! Mulher consciente abandona a oficina e terás contribuído para o teu próprio bem-estar.

Operário consciente não permitas que as tuas filhas e companheiras ingressem na oficina e terás contribuído valiosamente para o atenuamento da crise que presentemente te atormenta.

Acabemos, pois!...Mulheres como mulheres, homens como homens. Para a mulher o lar, para o homem a oficina" (ver Mónica, 1982, pp. 152-154).

\section{Horário de trabalho.}

Nesta temática inclui-se a legislação sobre descanso semanal, mas também a que se refere ao horário de trabalho propriamente dito. No que respeita ao descanso semanal tinha sido legislado em 1907, sendo fixado ao domingo, com excepção de determinadas áreas profissionais. Novo decreto é publicado logo em Janeiro de 1911, e em versão reformulada em Março seguinte, revogando o anterior de 1907, sem introduzir alterações de fundo - mantém-se o descanso semanal de 24 horas, se possível ao domingo, se não "num dos primeiros três dias normais depois do domingo em que trabalharam". De notar a consagração, ainda que incipiente, da irrenunciabilidade do direito ao descanso, ao prever-se que "a renúncia do assalariado ao descanso semanal não produz efeito em juízo". Exceptuando-se o decreto no 15 513, de Maio de 1928, que vem esclarecer dúvidas sobre a sua aplicação, o citado decreto de 1911 manteve-se em vigor até 1933. De referir apenas que a Convenção da OIT sobre descanso semanal na indústria, de 1919, foi ratificada por Portugal em 1928.

Chegámos a 1910 sem legislação geral sobre horário de trabalho. Havia limitações em matéria de horário de trabalho por via dos trabalhadores envolvidos, caso das mulheres e dos menores, e por via da natureza das actividades exercidas, caso das indústrias dos tabacos. Neste caso, apesar das movimentações internacionais, Portugal não constituía uma excepção no concerto das nações europeias. Apenas em 1915 é fixado em dez horas por dia e sessenta por semana o tempo normal de trabalho diário no comércio e na indústria, definindo a lei as excepções a esta regra. No entanto esta legislação não chegou a ser regulamentada. Até ao ano de 1919 não se registaram alterações, passando-se da ausência de limites ao dia de oito horas e semana de quarenta e oito, que se aplicavam genericamente a todos os profissionais, com exclusão dos rurais e dos domésticos, por via do decreto № 5516, de 7 de Maio, e legislação complementar. Mencione-se ainda a ratificação pelo nosso país da convenção de Washington, no que respeita ao horário de trabalho nos estabelecimentos industriais, o que 
issn: $1808-799 \mathrm{X}$

ano 6 - número 7 - 2008

ocorreu em Julho de 1928. Assinale-se que, embora a ratificação tenha sido tardia, na verdade a legislação portuguesa cumpriu as determinações da Convenção logo desde o início, alargando até ao comércio o seu alcance. Foi este o quadro que vigorou até 1933 e, como sabemos, por muitos anos mais, em matéria de horário de trabalho.

As questões relativas ao horário de trabalho são as mais presentes nos documentos de imprensa analisados. Nos congressos operários interprofissionais trata-se de uma matéria omnipresente. Sendo objecto de teses autónomas, ou não, o horário de trabalho atravessa todos os congressos, na generalidade dos casos tendo por objectivo a defesa das oito horas e, excepcionalmente, em momentos de crise económica, pugnando pela redução a seis horas (Freire, 1992, p. 141).

Vejamos agora, em síntese, o que nos traz a imprensa generalista quanto ao decreto $\mathrm{n}^{\circ}$ 5516, de Maio de 1919, escolhido para ilustrar esta temática. As muitas repercussões deste normativo são particularmente significativas das tensões vividas na sociedade portuguesa patrões de um lado, trabalhadores por outro, esgrimem argumentos contra e a favor da jornada das 8 horas. Reivindicação operária com muitos anos, na verdade, em Portugal é concedida quase abruptamente, na sequência dos acordos de paz, que o país subscreveu enquanto beligerante, constituindo-se como membro fundador da OIT. Passámos da ausência de horário - a lei de 1915, das 10 horas de trabalho, que por nunca ter sido regulamentada, estava longe de conhecer aplicação generalizada - para o horário das 8 horas. Assim, as lutas adiaram-se para o momento posterior à publicação das leis, para o momento do efectivo cumprimento das normas. São essas lutas quotidianas que testemunham os periódicos consultados.

\section{Em jeito de conclusão.}

Feito o balanço de cada uma das temáticas, importa agora fazer algumas reflexões de conjunto. Regista-se uma evolução muito positiva quanto aos direitos consagrados na lei, designadamente em matéria de higiene, saúde e segurança e horário de trabalho. Sabe-se, contudo, que estes direitos consagrados na lei não eram de aplicação generalizada a todos os trabalhadores. Em todo o período em causa os rurais e os domésticos, mais de $50 \%$ da população activa, estavam fora do âmbito de aplicação de várias leis, nomeadamente a do horário de trabalho, porventura a mais simbólica no que respeita às conquistas dos trabalhadores.

Esta fraca cobertura dos trabalhadores pela lei era acompanhada pela exiguidade dos direitos concedidos. Não se pode transpor o nosso olhar para a realidade da época sem cometer um assinalável erro metodológico. Contudo, reflictamos, por exemplo, quanto à protecção dada às mulheres e às crianças. Foi pouco o que se evoluiu no período estudado $\mathrm{e}$ 
issn: $1808-799 \mathrm{X}$

\section{ano 6 - número 7 - 2008}

os direitos que a lei previa em 1933, aos nossos olhos, limitadíssimos: ter quatro semanas de licença pós-parto, trabalhar legalmente aos 12 anos.

Outra exiguidade a assinalar. Não era esse o intuito, nem pretendo tirar conclusões, que apenas outros estudos poderão apontar, mas estou convicta de que o grau de efectividade do cumprimento dos direitos que a lei ia consagrando era pequeno. Todas as leituras feitas para isso apontam, desde a imprensa operária - na qual a reclamação tem presença obrigatória -, à imprensa generalista, como, e sobretudo, pelos preâmbulos das leis, em que é frequente o próprio legislador referir o incumprimento anterior das normas como justificação para uma nova formulação legal.

A dimensão deste incumprimento justificará, porventura um futuro estudo. Identificar, caso a caso, os instrumentos fiscalizadores existentes ou não existentes e analisar as razões que levaram à ineficácia da aplicação prática das normas será um campo vasto de trabalho. $A$ própria emergência de formas alternativas de controlo, de natureza sindical (Freire, 1992, p. 155), quanto ao horário de trabalho e outras normas, aponta para a inoperância e falibilidade do sistema público enquanto mecanismo de garantia do cumprimento da legalidade em matéria laboral.

Este sistemático incumprimento da legislação, que os próprios normativos evidenciam, remete para um traço comum, a tradição retórica da produção legislativa portuguesa, que parece perpetuar-se. É como se o Estado se "desobrigasse" pela lei quanto à urgência e necessidade de mudar o real.

Aliás, esta situação assemelha-se à vivida em França, cuja cultura jurídico-institucional tem um peso determinante em Portugal. Já em 1922 Georges Scelle assinalava como uma das características da legislação operária francesa o facto de ser, por vezes, uma "legislação de fachada" (ver Supiot, 1989).

O facto de a legislação assumir um carácter programático, como que modelando e antecipando a solução que a realidade vai encontrar, adia muitos dos conflitos laborais para um momento posterior à publicação das leis. Exagerando, poder-se-ia dizer que se luta, não pela lei que consagra os direitos, mas sim para que essa lei seja efectivamente cumprida.

Fazendo uma ponte para os dias de hoje apenas a menção ao artigo 125ํำ do Código do Trabalho português, entre muitas outras hipóteses de exemplo. Esta norma estabelece o direito de cada trabalhador a 35 horas de formação certificada anual. Todos conhecemos o exíguo cumprimento da mesma norma e conhece-se também a inscrição nas reivindicações sindicais da luta pela sua efectivação. Casimiro Ferreira assinala também, nos dias de hoje, esta "discrepância entre os quadros legais e as práticas sociais e que se traduz na não aplicação ou na aplicação selectiva da lei" e a "contradição entre os quadros legais que continuam a 
issn: $1808-799 \mathrm{X}$

\section{ano 6 - número 7 - 2008}

oferecer ampla protecção aos trabalhadores e as práticas sociais que os violam" (1994, pp. 9394), o que reforça a convicção de um traço de permanência na sociedade portuguesa quanto a esta tradição retórica da legislação.

Se bem que o alcance da análise efectuada quanto às repercussões na imprensa e na sociedade seja muito limitado, devo referir que, quanto aos congressos operários, é de notar uma enorme atenção à lógica de organização endógena (ver Freire, 1992) e relativo o interesse demonstrado quanto aos temas analisados, com excepção do horário de trabalho que mobiliza muitas discussões. Quanto à imprensa generalista, reflecte as tensões da sociedade portuguesa, em particular também no que se refere ao horário de trabalho, mostrando a previsível conflitualidade entre patrões e trabalhadores, e respectivas estruturas, quanto à aplicação prática da lei.

Outra nota prende-se com o peso determinante que teve a influência internacional na forma como o Estado exerceu a sua função legislativa em matéria laboral. Não se podem escamotear os jogos internos, nem as pressões das forças políticas e sociais em presença na sociedade portuguesa, mas a análise dos normativos e seu histórico, evidencia o decisivo contributo que as dinâmicas internacionais tiveram neste processo.

O facto de o processo interno de ratificação das normas internacionais ser lento, e isto sucede antes e depois da criação da OIT, mesmo sendo Portugal um dos seus membros fundadores, não impede que a produção legislativa portuguesa reflicta as últimas tendências internacionais. Exemplo paradigmático desta situação é a adopção das 8 horas logo em 1919, ainda que a ratificação da convenção apenas aconteça em 1928.

Assinale-se também o processo, descontínuo, de evolução do Estado, de um modelo liberal, com pouca intervenção em matéria social para um modelo corporativo e "protector", que a análise diacrónica dos normativos nos transmite (Miranda, 1982, p. 260).

Os textos constitucionais são a melhor ilustração deste processo: a Constituição de 1911, emergente da nova ordem instituída pela República, apresenta um projecto político assente no liberalismo democrático e não ainda uma qualquer forma de democracia social, não prevendo em matéria de direitos, liberdades e garantias qualquer novidade face aos textos constitucionais anteriores; já a Constituição de 1933 traduz um compromisso entre "os cem anos de constitucionalismo liberal e a filosofia política de Salazar" (Miranda, 1982, p. 259), com o aparecimento de vários direitos sociais, enquadrados no projecto corporativo. Ora, não tendo havido um salto abrupto, a evolução dos normativos que foram sendo publicados no período, são testemunho desta paulatina transformação, de que as duas Constituições, cujas datas correspondem às balizas temporais deste trabalho, são o exemplo vivo. 
issn: $1808-799 \mathrm{X}$

ano 6 - número 7 - 2008

Também esta maior presença do Estado não é exclusiva de Portugal, correspondendo a dinâmicas internacionais de alargamento da intervenção pública na vida social, em particular na esfera laboral.

Por último, é de assinalar o facto de, ao contrário do que uma história feita apenas sobre acontecimentos políticos nos pode induzir, não existirem rupturas significativas em matéria de produção legislativa. Não existe um antes e um depois do 5 de Outubro, radicalmente diferentes, como também não parece existir um antes e um radicalmente diferente depois de 1933. Na verdade, mudam as instituições, mudam as regras do jogo dos actores sociais, mas há uma dinâmica que permanece, interesses conflituais entre patrões e trabalhadores que não se alteram, um peso da influência externa que se afigura determinante. As rupturas políticas entre a Monarquia, a República e o Estado Novo são radicais e, em muitos aspectos, dramáticas. Mas é preciso reconhecer que, em vários casos, a legislação do período republicano mais não faz do que actualizar e melhorar a que vinha da Monarquia, que por sua vez provinha da adaptação de normas e formas de pensar internacionais. Por outro lado, o Estatuto do Trabalho Nacional recebeu, pelo menos parcialmente, a legislação anterior sobre protecção social dos trabalhadores, embora the tenha dado uma nova formulação.

\section{2 - Para uma Leitura Contemporânea.}

"Passado, por definição, é o já não-vivente, o inactual, o histórico. Ora como o presente é, de certo modo e até certo ponto, a consequência ou a projecção do passado, o filho de múltiplos sucessos que foram, compreende-se que o presente necessite de mergulhar os olhos no pretérito, e o disseque, o ilumine, ou - por outras palavras - o compreenda. Todo o filho adulto deve estudar o pai. Estudando-o, estuda-se implicitamente no pai. A sociologia mostra-nos que na história não existem brechas ou soluções de continuidade; os factos não brotam por geração espontânea; encadeiam-se casualmente uns nos outros, ao longo da estrada do tempo; a vida é teia complexa" (1936루).

O filósofo português Sílvio Lima caracterizava deste modo, em 1936, em artigo publicado no Diário de Lisboa, a importância que deverá ter para nós a leitura crítica do passado. Na verdade, se fizermos o exercício de retirar a máscara do tempo, as grandes questões que se nos colocam são semelhantes às que ocupavam os nossos antepassados, nas primeiras décadas do século XX.

Procurarei agora reflectir tendo presente esse passado, fazendo um paralelismo com os dias de hoje. Começarei por pensar nos trabalhadores na actualidade e interrogar-me-ei sobre quem são agora os excluídos pela lei; qual é o papel do Direito e das instâncias de regulação 
issn: $1808-799 \mathrm{X}$

ano 6 - número 7 - 2008

internacional em matéria laboral hoje em dia e, finalmente, sobre o papel a desempenhar pelos interessados no desenho do conteúdo das relações laborais.

Independentemente da natureza e extensão dos direitos que a lei ia consagrando uma outra questão se colocava então: quem eram os abrangidos? A quem aproveitava a lei? Como vimos, no período republicano a lei genericamente aplicava-se ao proletariado, ou talvez melhor, aos assalariados da indústria e do comércio, deixando de fora uma forte percentagem de pessoas activas. A expectativa era que se alargasse o seu âmbito de abrangência a todos os trabalhadores.

Hoje teremos de colocar a questão noutros termos. Várias obras de referência anunciam o fim do trabalho tal como o conhecemos, como por exemplo: Jeremy Rifkin, La fin du travail, 1996; André Gorz, L'adieu au prolétariat: Misères du présent, richesse du possible, 1997; André Gorz, Métamorphoses du travail, 2004; Bernard Perret, L'avenir du travail, 1995; Dominique Schnapper, Contre la fin du travail, 1997; Guy Aznar, Emploi: la grande mutation, 1996. Apesar de perspectivas nem sempre coincidentes todos apresentam cenários diferentes, que hoje já são presente, para a realidade trabalho.

O emprego assalariado foi durante dezenas de anos a pedra angular da nossa organização económico-social. Deste emprego dependia a percepção de um salário, mas também as prestações sociais, ligadas a uma ocupação futura ou passada (reformas, subsídios de desemprego e doença). A realidade hoje é diferente, como diz Hugues de Jouvenel:

\begin{abstract}
"Este modelo está em perigo por causa da mundialização da economia, da evolução das tecnologias, da mutação do mundo do trabalho, da evolução das estruturas sociais (a começar pela demografia), da evolução dos valores... [...] As empresas conservarão um núcleo duro restrito de pessoal permanente e para o resto buscarão, em função das necessidades, competências de pessoas empregadas através de contratos de duração determinada, ou até mais a colaboradores que a assalariados. As pessoas, em vez de procurarem um emprego, serão levadas a ser empresários independentes vendendo os seus serviços, ou talvez melhor estabelecendo parcerias temporárias" (1995, p. 9).
\end{abstract}

André Gorz, por sua vez, em Les métamorphoses du travail, prevê, a curto prazo, uma inevitável precarização das relações laborais. Divide o pessoal das empresas em três núcleos: o estável, ocupando previsivelmente $25 \%$ do total, e que corresponde ao nosso conceito actual de trabalhador dependente permanente; a mão-de-obra periférica, em duas camadas que são constituídas por trabalhadores com vínculo mas não qualificados, que podem ser substituídos a qualquer momento, que constituirão outros $25 \%$ e por trabalhadores precários, que conjuntamente com a mão-de-obra externa, subcontratada farão os restantes 50\% (2004, pp. 
issn: $1808-799 X$

ano 6 - número 7 - 2008

113-114). José Eduardo Faria, por sua vez, fala de três níveis: um núcleo cada vez menor de trabalhadores polivalentes estáveis, trabalhando em tempo integral, com direitos trabalhistas e benefícios sociais; uma mão-de-obra periférica de baixa qualificação, flutuando ao acaso da conjuntura económica, demissível segundo as conveniências das empresas e os trabalhadores "externos" para com os quais as empresas não têm maiores obrigações jurídicas (2004, pp. 230-231).

As mutações em curso do mercado de trabalho caracterizam-se pela diminuição acentuada do peso do assalariado clássico, com a precarização dos vínculos contratuais (ver Ferreira \& Costa, 1999) e trazem consigo a geração dos trabalhadores poliactivos:

"Primeiro existiu um homem de um só trabalho, na sua empresa, para toda a vida. O seu filho conheceu várias empresas. O neto pode exercer várias profissões durante uma carreira mais movimentada. Hoje a nossa geração descobre o que será uma parte dos trabalhadores do futuro: os homens poliactivos. Homens e mulheres que conduzirão simultaneamente várias carreiras" (Buhler \& Ettighofer, 1995, p. 203).

Chamemos-lhe este ou outro nome a verdade é que as formas de emprego na sociedade actual assumem múltiplas formas, cada vez mais diversificadas e menos rígidas, num jogo laboral cujas regras mudam inexorável e permanentemente. Este quadro evoca-nos Calvino (1998) e a capacidade que teve de intuir a natureza do novo milénio, apontando para o cruzamento de três das suas propostas: leveza, rapidez e multiplicidade.

À medida que se diz adeus ao proletariado e se criam novas formas, tantas vezes atípicas, de emprego, o que resta dos direitos dos trabalhadores? Como falar de horário de trabalho neste contexto, se cada um é dono do seu tempo e o "vende" a quem o quer comprar? Como falar de seguros de acidentes e doenças se a responsabilidade é agora de cada um, muitas vezes trabalhando em casa ou virtualmente? Caminhamos para cenários em que o tempo de trabalho se tornará uma realidade puramente individual, praticamente impossível de apreender e de regular colectivamente (ver Perret, 1995).

Ontem como hoje muitos, talvez mais, ficarão de fora desse núcleo básico de direitos laborais, que todos acreditávamos ser uma conquista para todo o sempre e para todos quantos trabalham. A realidade mudou, as questões permanecem, com outro rosto.

Ontem como hoje o Direito, enquanto conjunto de normas que regulam a vida social, será chamado a intervir, seja emergindo das estruturas de cada país, seja resultando das instâncias de concertação internacional. Voltemos a Sílvio Lima: 
issn: $1808-799 \mathrm{X}$

ano 6 - número 7 - 2008

\begin{abstract}
"A Sociedade das Nações representa uma vita nuova, ela é o direito tornado disciplina universal; ela é o mundo juridificado até à medula. Se o direito nacional aniquila a «lei da selva» entre os particulares, a Sociedade das Nações aniquila a «lei da selva» entre os povos.

O mundo marcha, com passo invencível, para esse nova ética internacional. Não nos iludamos com os pequenos retrocessos, ou com as paragens bruscas que nessa marcha surgem, como episódios de viagem.

Tolstoi disse, e com razão, a águia, que agora voa no azul, não pode regressar ao ovo donde saiu um dia, quebrando a casca" (1936b).
\end{abstract}

A Sociedade das Nações já não existe há muito. Mas o papel regulador das instâncias internacionais, que se encontra implícito no texto citado, não sofreu alterações. A OIT, emergente da Sociedade das Nações, continua a exercer a sua função e muitas outras instâncias, designadamente da União Europeia, constituem fóruns de discussão e decisão sobre matérias laborais.

Há cem anos assistia-se a vivos debates sobre o risco que o desenvolvimento da legislação operária em cada país poderia acarretar, em matéria de concorrência internacional, pelos gastos suplementares que supunha. Este era um argumento a favor de uma regulamentação internacional do trabalho: "Logo que esses encargos fossem iguais para as indústrias de todos os países tal perigo desapareceria e assim veríamos suprimido um dos principais obstáculos que se opõem à protecção legal dos trabalhadores" (Ulrich, 1906, p. 17).

Os desafios que se colocavam então ao Direito assumiam uma componente de regulação interna a cada país, mas também uma dimensão externa, que, como vimos, se interpenetravam. Hoje não é diferente. Apesar de permanecerem enquanto espaços autónomos, com história e especificidade próprias, na realidade, por razões económicas e políticas, os países viram as suas fronteiras esbatidas, em particular no caso da Europa.

Não querendo entrar no discurso recorrente da globalização ou da "ordem global", não podemos também ignorar o conceito (ver Gonçalves, 2000). Recorrendo às palavras certeiras de Lucien Febvre, nas suas lições no Collège de France, em 1944, palavras hoje já longínquas, mas sempre actuais: "Já não se pode falar de Europa sem referir o universo inteiro" (2001, p. 332).

É, pois, de um mundo à escala global que temos de falar quando abordamos a regulação das relações de natureza laboral. Não podemos ignorar o desempenho fulgurante das economias asiáticas e o que pressupõe em matéria de exploração dos trabalhadores, seja quanto aos horários praticados, seja quanto à utilização de mão-de-obra menor, seja ainda quanto à manipulação de substâncias tóxicas sem protecção adequada. Conforme referem 
issn: $1808-799 \mathrm{X}$

ano 6 - número 7 - 2008

Casimiro Ferreira e H. Augusto Costa, "o desafio de uma globalização das relações laborais que sirva de contrapeso à globalização dominante encontra-se na ordem do dia" (1999, p. 156).

São várias as dimensões em que se espera uma resposta do Direito. Num primeiro plano espera-se a generalização mundial de regimes de protecção, que para alguns de nós constituíram uma conquista de há muito. Num outro plano exige-se uma criatividade sem limites que permita, perante a multiplicidade de formas que assume o trabalho e o emprego, criar normas comuns de regulação. Não se sabe qual o caminho, mas sabe-se que é necessário chegar a um mínimo denominador comum de direitos laborais, independente de todas as variantes que assuma a relação laboral. Estas dimensões jurídicas jogam-se no plano nacional e internacional, o que nos leva a depositar esperanças na capacidade de renovação das instâncias que se dedicam à realidade laboral.

José Eduardo Faria, ao mesmo tempo que assume a implausibilidade deste "direito social" explica a continuidade da sua presença na agenda contemporânea (2004, pp. 283-285). Por seu turno, Alain Supiot tem vindo a reflectir sobre estes temas e tem publicado várias obras em matéria de política social, designadamente sobre o direito ao trabalho e sobre as alterações da legislação do trabalho no contexto das profundas mutações, sociais, económicas e tecnológicas que atravessamos. Por iniciativa da Comissão Europeia, em 1996 iniciou-se uma reflexão, prospectiva e interdisciplinar, sobre as transformações do trabalho e o futuro do direito do trabalho na Europa. Ao apresentar as principais linhas do relatório deste estudo, Alain Supiot traça as fronteiras do direito do trabalho, do estatuto profissional dos trabalhadores, do tempo de trabalho, da representação e negociação colectiva e ainda do papel do Estado. Sem detalharmos o seu pensamento apontaremos apenas para um dos pontos centrais da sua reflexão:

\begin{abstract}
"Mais do que o de protecção social, o conceito de cidadania social parece adequado para sintetizar hoje os objectivos do relançamento do direito do trabalho e do direito social em geral. Apesar da diversidade de concepções nacionais de cidadania, este conceito poderia tornar-se uma das pedras angulares do direito social à escala europeia. É englobante (cobre diversos direitos, não apenas o da pertença a esquemas de segurança social); liga os direitos sociais à noção de integração social e não somente à de trabalho $\mathrm{e}$ sobretudo supõe a ideia de participação. A cidadania pressupõe, com efeito, a participação das pessoas envolvidas na definição e concretização dos seus direitos" (1999, p. 33).
\end{abstract}

Retenhamos estes dois conceitos, de cidadania social e de participação, referidos por Alain Supiot. No mesmo sentido, Maria Eduarda Gonçalves também os mobiliza, sublinhando "a importância de alargar e reforçar as instâncias de acesso à informação e participação, como condição do pleno exercício da cidadania na sociedade contemporânea” (2000, p. 273). 
issn: $1808-799 \mathrm{X}$

ano 6 - número 7 - 2008

O nosso raciocínio final não ficaria completo sem uma palavra para o papel a desempenhar pelas pessoas, vistas individualmente como prestadoras de trabalho ou vistas como sujeitos das relações laborais (patrões e empresários ou trabalhadores), e pelas organizações em que se mobilizam, bem como para a existência de tensões sociais que necessariamente acontecem quando se trata alterar as condições de trabalho. Sem entrar na discussão sobre o conceito de classe social, permitimo-nos evocar a visão de Pierre Bourdieu (1984) para acentuar a dimensão política que deve revestir a mobilização dos actores sociais, de forma a criar e consolidar um sentimento de pertença a um mesmo grupo. Neste plano estamos longe da realidade dos anos 1920, em que a profissão exercida aglutinava os trabalhadores (os tipógrafos, os tanoeiros, as costureiras, etc.), conforme explica João Freire (1992), sendo necessário agora encontrar um outro fio condutor, porventura a própria natureza ou ausência de vínculo laboral (os prestadores de serviço, os trabalhadores ao serviços de empresas de trabalho temporário, os contratados a termo), que viabilize a mobilização dos trabalhadores e das suas organizações, sindicais ou outras, em torno das questões que thes são comuns.

Será porventura necessário imaginar formas diferentes de viver, na esfera laboral, a cidadania e a participação, de que nos fala Alain Supiot, mas é inevitável que assim seja para que o direito do trabalho e o direito social continuem a enquadrar as múltiplas relações que se estabelecem nesta esfera, adaptando-se às sempre novas realidades emergentes. Na verdade, é possível, como afirma Pierre Bourdieu, que tenha diminuído a "grande miséria do mundo", mas nem por isso têm deixado de se multiplicar "as condições favoráveis para um desenvolvimento sem precedentes de todas as formas da pequena miséria" (1993, p. 11). Pensar os direitos dos trabalhadores, hoje, só faz sentido se tivermos a consciência aguda desta realidade.

Com estas breves notas pretendi deixar pistas sobre o paralelismo possível entre o período que analisei (1910 a 1933) e a actualidade. O mundo mudou profundamente, mas há questões de fundo que permanecem, embora com outras roupagens. Continuam a existir trabalhadores excluídos da protecção legal geral. Mantêm-se os desafios das várias instâncias nacionais e internacionais que se ocupam do direito do trabalho. A mudança, ontem como hoje, está na ordem do dia, exigindo um constante esforço de adaptação e criatividade. Saber ler criticamente este passado poderá constituir um poderoso instrumento de trabalho para os desafios que se nos colocam no presente. 
issn: $1808-799 X$

ano 6 - número 7 - 2008

Apesar da aproximação que vem da história e da língua comuns, Portugal e o Brasil vivem em profundo desconhecimento um do outro. Em Portugal pouco se sabe da história do trabalho no Brasil e estamos convictos que o inverso é também verdadeiro.

Do nosso ponto de vista, seria muito interessante conhecer a evolução do trabalho no Brasil no chamado período da "República do café com leite", com o qual coincide em boa parte a experiência da $1 \stackrel{\text { a }}{ }$ República portuguesa, e o modo como a regulação jurídica do trabalho se foi conformando, face à situação interna e às influências internacionais. Analisar comparativamente o acolhimento e recepção das convenções da Organização Internacional do Trabalho em ambos os ordenamentos seria, certamente, uma frutuosa pista de investigação.

O aprofundamento e a partilha dos conhecimentos nesta área poderá estreitar laços entre quem se dedica ao tema de um lado e do outro do Atlântico e até contribuir para um outro olhar sobre a realidade laboral actual, com todos os desafios que apresenta. Com estas notas esperamos ter contribuído modestamente para essa ponte de conhecimento.

\section{Referências bibliográficas}

AZNAR, Guy (1996), Emploi : la grande mutation. Paris: Hachette.

AZNAR, Guy (1993), Travailler moins pour travailler tous. Paris: Syros éditeur.

BOURDIEU, Pierre (1984), “Espace social et genèse des classes », In: Actes de la recherche en sciences sociales, $\mathrm{n}{ }^{\circ} 52-53$.

BOURDIEU, Pierre (1993), La misère du monde. Paris: Seuil.

BUHLER, Nicolas \& ETTIGHOFER, Denis (1995), "L'homme polyactif”. In: Gérard Blanc (dir.), Le travail au XXlème siècle. Paris: Dunod.

CALVINO, Italo (1998), Seis propostas para o próximo milénio. Lisboa: Teorema.

FARIA, José Eduardo (2004), O Direito na economia globalizada. São Paulo: Malheiros Editores.

FEBVRE, Lucien (2001), A Europa - Génese de uma civilização. Lisboa: Teorema.

FERREIRA, António Casimiro (1994), «O Estado e a resolução dos conflitos de trabalho», In: Revista Crítica de Ciências Sociais, № 39, pp. 89-117.

FERREIRA, António Casimiro; COSTA, Hermes Augusto (1999), «Para uma sociologia das relações laborais em Portugal», In: Revista Crítica de Ciências Sociais, no 52/53), pp. 141-162. FREIRE, João (1992), Anarquistas e operários - Ideologia, ofício e práticas sociais: o anarquismo e o operariado em Portugal, 1900-1940. Porto: Afrontamento. 
issn: $1808-799 X$

ano 6 - número 7 - 2008

GONÇALVES, Maria Eduarda (2000), "Cidadania na sociedade da informação e do risco: da análise social à análise dos direitos», In: José Manuel Leite Viegas e Eduardo Costa Dias (org.), Cidadania, Integração, Globalização. Oeiras: Celta Editores.

GORZ, André (2004), Métamorphoses du travail - Critique de la raison économique, $2^{a}$ ed. Paris: Éditions Gallimard.

GORZ, André (1997), L'adieu au prolétariat: Misères du présent, Richesse du possible. Paris: Éditions Galilée.

JOUVENEL, Hugues (1995), «La société française à l'horizon 2010: réinventer l'univers du travail». In: Gérard Blanc (dir), Le travail au XXlème siècle. Paris: Dunod, pp. 9-34.

LIMA, Sílvio (1936a), «Passado, presente e futuro», Diário de Lisboa, № 4838, de 9 de Maio.

LIMA, Sílvio (1936b), «Vita nuova», Diário de Lisboa, № 4764, de 22 de Fevereiro.

MIRANDA, Jorge (1982), Manual de Direito Constitucional. Coimbra: Coimbra Editora.

MÓNICA, Maria Filomena (1982), A formação da classe operária portuguesa - Antologia da imprensa operária (1850 - 1934). Lisboa: Fundação Calouste Gulbenkian.

PERRET, Bernard (1995), L'avenir du travail. Les démocraties face au chômage. Paris: Éditions du Seuil.

RIFKIN, Jeremy (1996), La fin du travail. Paris: Éditions La Découverte.

RODRIGUES, Cristina (2006). Trabalhar em Portugal (1910 - 1933) - Análise da legislação sobre os direitos dos trabalhadores. [Policopiado]. Lisboa : ISCTE. Dissertação de Mestrado em Sociologia do Trabalho das Organizações e do Emprego.

SCHNAPPER, Dominique (1997), Contre la fin du travail. Paris: Les Éditions Textuel.

SUPIOT, Alain (1989), "Déréglementation des relations de travail et auto réglementation de l'entreprise», Droit Social, no 3, pp. 195-205.

SUPIOT, Alain (1999), «Transformations du travail et devenir du droit du travail: une prospective européenne»Revue Internationale du Travail, vol. 138, no 1, pp. 33-52.

ULRICH, Rui Ennes (1906), Legislação operária portuguesa. Coimbra: França Amado Editor. 